

\section{THE NATIONAL BUREAU OF STANDARDS}

\section{Functions and Activities}

The functions of the National Burcan of staudards are set forth in the Act of Congress, March 3. 1901, as ancuded by Congress in Public Law 619, 1950. These include the development and maintenance of the national standards of measurement and the provision of means and methods for making measurements consistent with these standards: the determination of physical constants and properties of materials; the development of methods and instruments for testing materials, devices, and structures: advisoty services to Government Agencies on scientific and technical problems; invention and development of devices to serve special needs of the Government; and the development of standard practices, codes and specifications. The work includes basic and applied research, development, engineering, instrumentation, testing, evaluation, calibration services, and various consultation and information services. A major portion of the Bureau's work is performed for other Government Agencies, particularly the Department of Defense and the Atomic Energy Commission. The scope of activities is suggested by the listing of divisions and sections on the inside back cover.

\section{Reports and Publications}

The results of the Bureau's work take the form of either actual equipment and devices or published papers and reports. Reports are issued to the sponsoring agency of a particular project or program. Published papers appear either in the Bureau's own series of publications or in the journals of professional and scientific societies. The Bureau itself publishes three monthly periodicals, available from the Government Printing Otfice: The Journal of Research, which presents complete papers reporting technical investigations; the Technical News Bulletin, which presents summary and preliminary reports on work in progress; and Basic Radio Propagation Predictions, which provides data for determining the best frequencies to use for radio communications throughout the world. There are also five series of nonperiodical publications: The Applied Mathenatics Series, Circulars, Handbooks, Building Materials and Structures Reports, and Miscellaneous Publications. 


\section{NATIONAL BUREAU OF STANDARDS REPORT NBS PROJECT \\ NBS REPORT \\ $8300-11-8303$ \\ January 23, 1958 \\ 5548}

A PRECISION FREQUENCY STANDARD FOR X-BAND

by

M. C. Thompson, Jr., M. J. Vetter and Donald $\mathrm{M}$. Waters

NBS

U. S. DEPARTMENT OF COMMERCE

NATIONAL BUREAU OF STANDARDS

BOULDER LABORATORIES

Boulder, Colorado 


\title{
IMPORTANT NOTICF
}

\author{
NATIONAL BUREAU OF STANC Approved for public release by the \\ ments intended for use within th Director of the National Institute of \\ is subjected to additional evaluat \\ tion, or open-literoture listing of Standards and Technology (NIST) on \\ mission is obtained in writing fran October 9, 2015.
25, D. C. Such permission is not \\ been specifically prepared if that
}

gress occounting docu. 5 formally published it I, reprinting, reproducautharized unless perStandards, Washington 


\title{
A PRECISION FREQUENCY STANDARD FOR X-BAND
}

\author{
by \\ M. C. Thompson, Jr., M. J. Vetter and Donald M. Waters \\ National Bureau of Standards \\ Boulder, Colorado
}

\section{ABSTRACT}

A compact microwave generator (Fig. 1) is described in which an X-band reflex klystron is stabilized by a quartz-crystal secondary standard. Frequency stability of the order of several parts in $10^{9}$ over periods of the order of a day has been obtained. A technique for obtaining continuous wide-range variation of output frequency with stability of the order of 1 part in $10^{\circ}$ is described.

The generation of microwave signals of stable frequency has been accomplished during recent years by the stabilization of reflex klystrons with cavity resonators (such as the Pound oscillator) and by direct multiplication from lower frequency quartz oscillators. A third approach which appears to have numerous advantages over the two mentioned above uses a phase-locking technique (1) in which a small amount of microwave energy is used to establish the operating frequency of a relatively high-powered klystron. The general method of operation is shown in Fig. 2. A crystal oscillator at 10 Mc drives two vacuum tube multipliers to give about $1 / 2$ watt output at $100 \mathrm{Mc}$. This is used to excite a silicon diode as a harmonic generator to produce small amounts of power at frequencies in the X-band, i.e., 9300,9400, $9500 \mathrm{Mc}$ etc. The power in these harmonics is mixed with a small amount of the output of the klystron. If the klystron is operating at its nominal frequency, for example, $9500.5 \mathrm{Mc}$, one of the beat frequencies present at the mixer will be $500 \mathrm{Kc}$. This signal is amplified and supplied to a phase discriminator where it is compared with a second $500 \mathrm{Kc}$ signal from an auxiliary crystal oscillator. Any shift in phase of the klystron appears as a shift in phase of the $500 \mathrm{Kc}$ beat and the discriminator responds with an error voltage to the klystron's repeller. Thus in normal operation, the klystron is held to an average output frequency determined completely by the $10 \mathrm{Mc}$ and the $500 \mathrm{Kc}$ crystals. Since the former is multiplied by about 1000, its stability 
practically determines the stability of the klystron. That is, a shift of 1 cps in the $10 \mathrm{Mc}$ oscillator produces a shift of $950 \mathrm{cps}$ in the klystron whereas a 1 cps shift in the $500 \mathrm{Kc}$ oscillator will appear as a 1 cps shift in the klystron's frequency. The detail circuit used is given in Fig. 3. It consists of a conventional amplifier with AGC driving a discriminator. The reference oscillator is a Pierce circuit. In the various klystrons which have been tried to date (VA-203B, V-201, and V-58) the 60-cycle modulation, due presumably to $A C$ heater operation, has been appreciable. To correct for this without going to a DC heater supply, a neutralizing signal is obtained from one of the heater transformers. The time constant of the error-signal circuit is adjustable. For most klystrons used, there is a definite, optimum setting for this time constant. A reset circuit is provided so that in the event of momentary interruption of operations which might cause the discriminator to lose control, the klystron is automatically swept slowly through the vic inity of the operating frequency until the discriminator regains control.

In normal operation, a $2^{\prime \prime} \mathrm{CRT}$ is used for observing the Lissajou's figure formed between the reference oscillator and the $500 \mathrm{Kc}$ IF frequency. The appearance of this figure is used as the criterion for adjustment of error-signal time constant, hum neutralization and general adjustment of repeller bias. The normal appearance is a rather clean ellipse or circle. Maladjustment of any of the above-mentioned controls is easily detected as a broadening of the pattern into a rectangle.

The two power supplies are sealed units using semiconductor rectifiers. One is rated at 350 volts at 20 ma (with built-in coldcathode voltage regulation) for the repeller bias and the other, 350 volts at 100 ma supplies the klystron anode and all control circuits.

The klystron and its associated plumbing are shown in Figs. 4 and 5. About $1 / 2$ watt of $100 \mathrm{Mc}$ signal is used to drive a $1 \mathrm{~N} 23 \mathrm{~B}$ silicon diode, mounted in a conventional waveguide holder, as a harmonic generator. A second 1 N23 acts as a mixer to form the beat between the harmonic energy and the klystron. A double waveguide " $T$ " is used for this purpose. The side arms of the " $T$ " are about two wave lengths apart with a small screw halfway between. The location of the screw is such that essentially all of the pcwer from the klystron passes out to the load. Adjusting the screw penetration provides control over the excitation of the mixer diode. A ferrite isolator follows the mixing system to reduce the effects of 

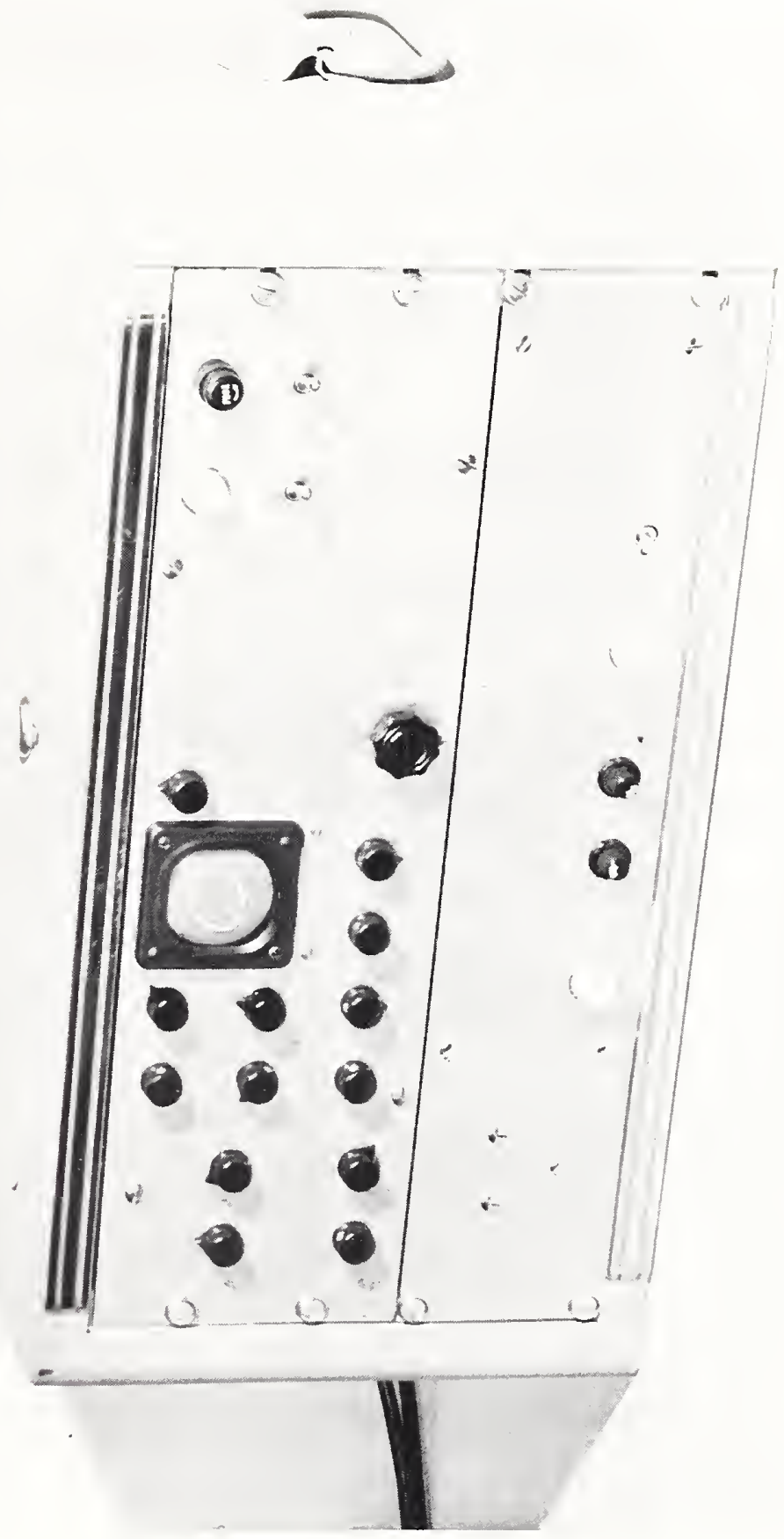

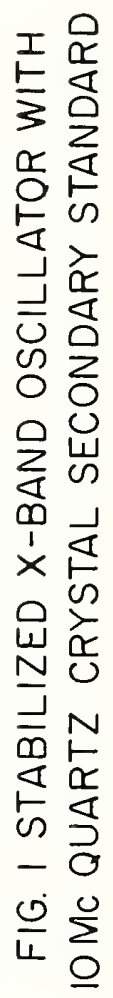




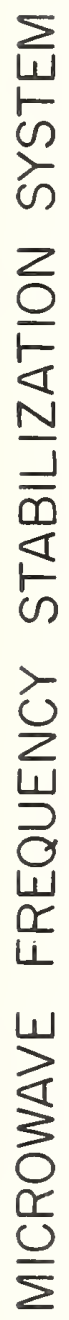

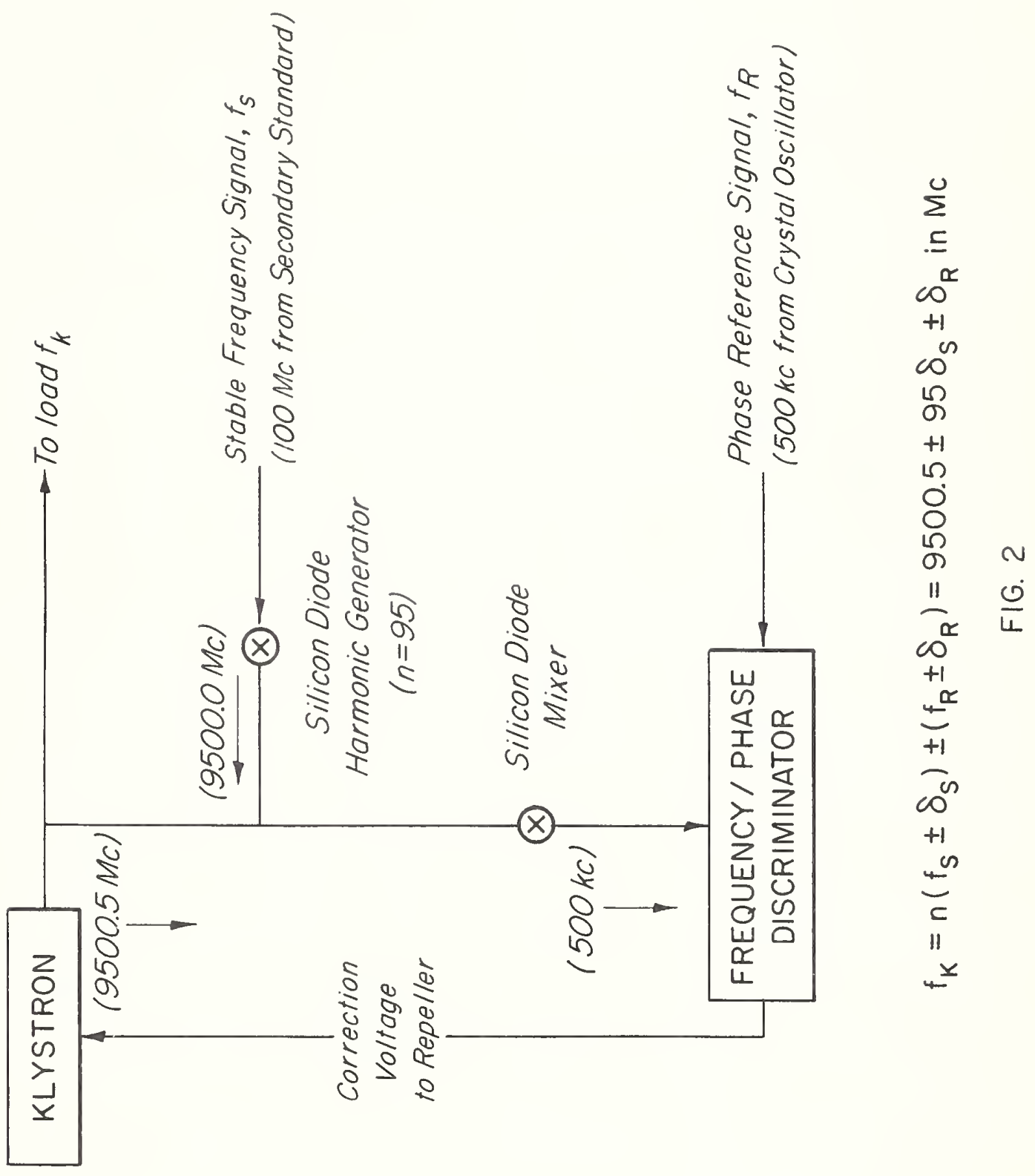





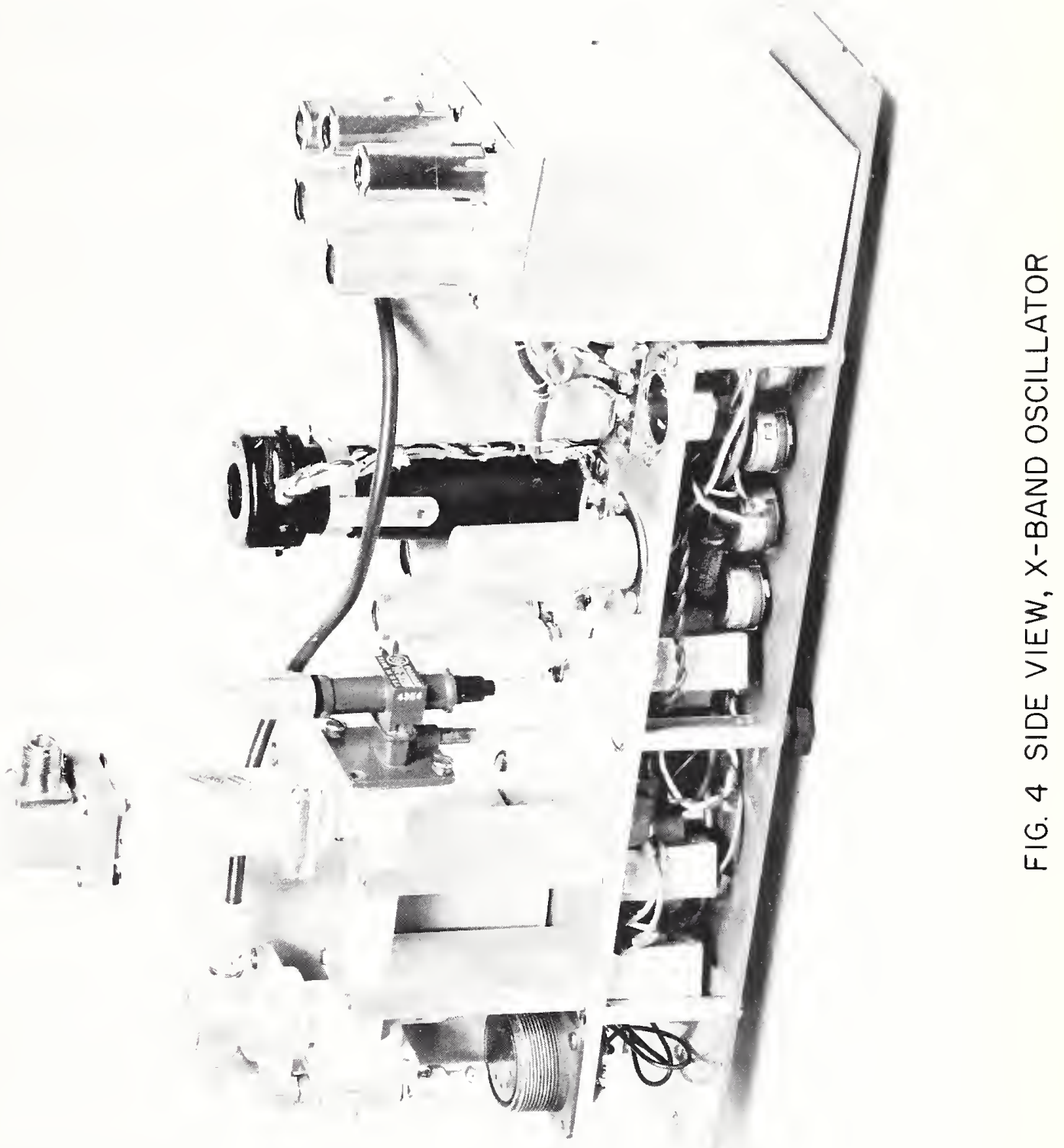




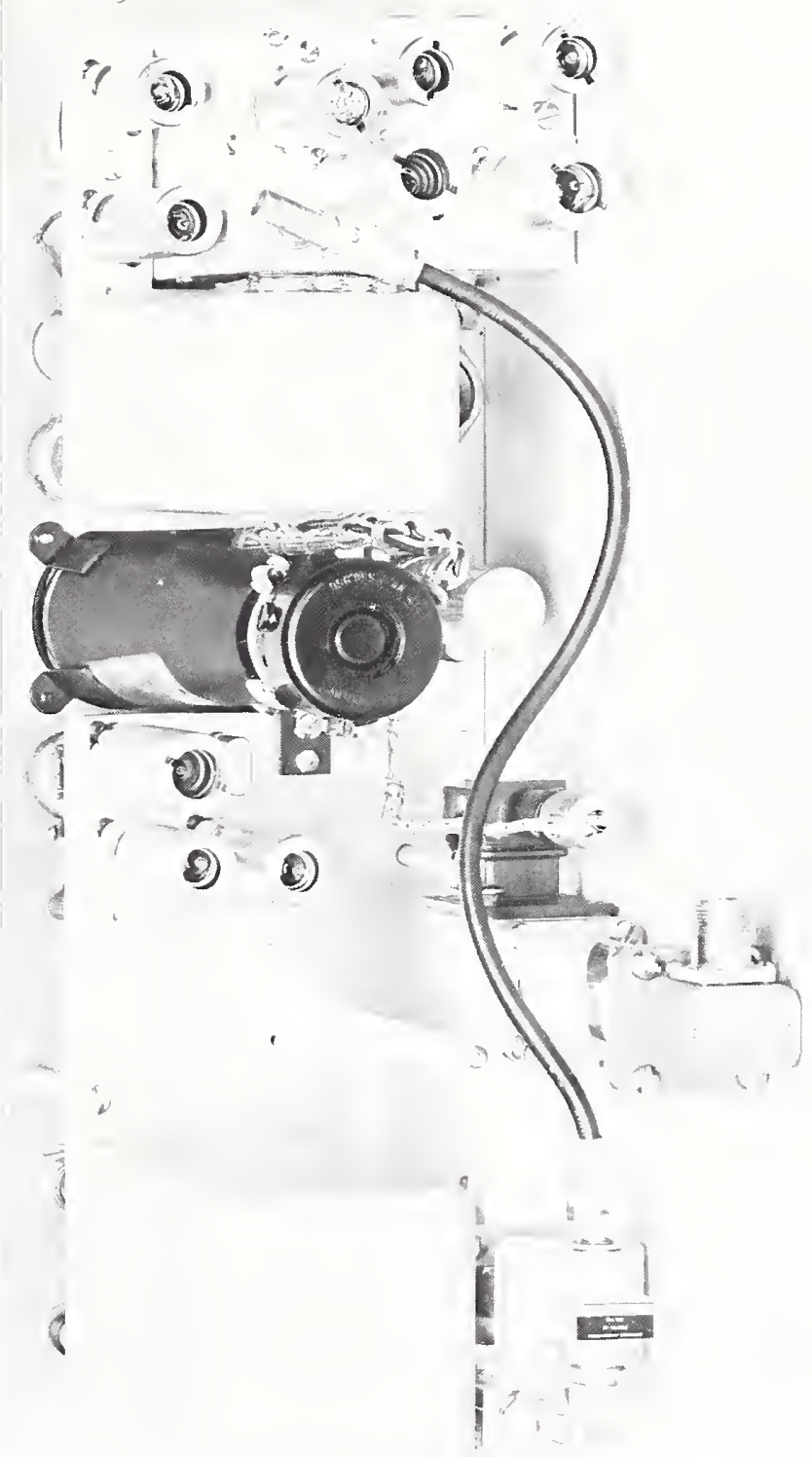

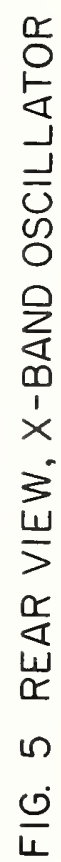


load changes on the mixing levels. Output may be obtained by waveguide plumbing or a waveguide-to-coax adapter and cable may be used.

The entire plumbing assembly may be readily removed from its support brackets in cases where the unit is used to drive an antenna as a transmitter. Provision is made for a suitable power cable to plug into the rear of the chassis in such cases.

The operation as described above is limited to several discrete frequencies. In the detail description, an operating frequency of $9500.5 \mathrm{Mc}$ was assumed, using the 95th harmonic of the $100 \mathrm{Mc}$ signal and having the discriminator phased to operate the klystron above the incoming harmonic. By simply reversing the phase of the discriminator the stable operating point for the klystron becomes 9499.5 Mc, thus giving a shift of $1 \mathrm{Mc}$ in the frequency of the klystron. A shift to a different harmonic, say the $93 \mathrm{rd}$ or $94 \mathrm{th}$, is also relatively straightforward. If the klystron is simply retuned until its output is in the vicinity of $9600.5 \mathrm{Mc}$, the system will stabilize to this frequency. In fact, the limit is essentially the range of operation of the klystron since all harmonics from 85 th to 96 th are approximately the same amplitude.

In addition to frequency shifts of $\mathrm{I} \mathrm{Mc}$ and $100 \mathrm{Mc}$ as just dis. cussed, it is also practical in this system to shift $10 \mathrm{Mc}$. This is the result of modulation which comes through the vacuum-tube multipliers from the $10 \mathrm{Mc}$ oscillator to $100 \mathrm{Mc}$. By simply retuning the klystron by means of the repeller bias it is practical to lock the klystron to a frequency either $10 \mathrm{Mc}$ below or $10 \mathrm{Mc}$ above any of the above mentioned $100 \mathrm{Mc}$ harmonics. In order to utilize this feature, an ordinary commercial wavemeter is added to the plumbing to permit easy identification of the harmonic or sideband which is controlling.

A further modification permitting continuous frequency variation is shown in Fig. 6. The beat frequency signal obtained from the mixer diode is fed into a conventional superheterodyne receiver and the phase-1ock discriminator is designed to operate at the IF of the receiver. The control loop now requires that the klystron operate at such a frequency that, when its output is mixed with the harmonic of the secondary standard, the resulting beat equals the frequency to which the receiver is tuned. Thus, using the figures given above, if the receiver were tuned to $2.310 \mathrm{Mc}$, the klystron would be stabilized at a frequency either higher or lower than 9500 by 

I. S. DEPARTMENT OF COMMERCEE

Sinclair Weeks, secretary

NATIONAL BUREAL OF STANDARDS

A. v. Astin, Director

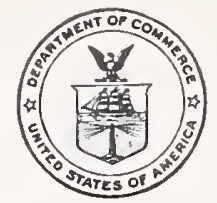

\section{THE NATIONAL BUREAU OF STANDARDS}

The scope of the scientific program of the National Bureau of Standards at laboratory centers in Washington, D. C., and Boulder, Colorado, is given in the following outline:

Washington, D.C.

Electricity and Electronics. Resistance and Reactance. Electron Tubes. Electrical Instruments. Magnetic Mcasurenents. Dielectrics. Engineering Electronics. Electronic Instrumentation. Electrochemistry.

Optics and Metrology. Photometry and Colorimetry. Optical Instruments. Photographic Technology. Length. Engincering Metrology.

Heat and Power. Temperature Physics. Thermodynamics. Cryogenic Physics. Rheology and Lubrication. Engine Fuels.

Atomic and Radiation Physies. Spectroscopy. Radionetry. Mass Spectrometry. Solid State Physics. Electron Physics. Atomic Physics. Nuclear Physics. Radioactivity. X-rays. Betatron. Nucleonic Instrumentation. Radiological Equipment. AEC Radiation Instruments.

Chemistry. Organic Coatings. Surface Chemistry. Organic Chemistry. Analytical Chemistry. Inorganic Chemistry. Electrodeposition. Gas Chemistry. Physical Chemistry. Thermochemistry. Spectrochemistry. Pure Substances.

Mechanics. Sound. Mechanical Instruments. Fluid Mechanics. Engineering Mechanics. Mass and Scale. Capacity, Density, and Fluid Meters. Combustion Controls.

Organic and Fibrous Materials. Rubber. Textiles. Paper. Leather. Testing and Specifications. Polymer Structure. Organic Plastics. Dental Research.

Metallurgy. Thermal Metallurgy. Chemical Metallurgy. Mechanical Metallurgy. Corrosion. Metal Physics.

Mineral Products. Engineering Ceramics. Glass. Refractories. Enameled Metals. Concreting Materials. Constitution and Microstructure.

Building Technology. Structural Engineering. Fire Protection. Air Conditioning. Heating, and Refrigeration. Floor, Roof, and Wall Coverings. Codes and Specifications. Heat Transfer.

Applied Mathematics. Numerical Analysis. Computation. Statistical Engineering. Mathematical Physics.

Data Processing Systems. SEAC Engineering Group. Components and Techniques. Digital Circuitry. Digital Systems. Analogue Systems. Application Engineering.

- Office of Basic Instrumentation

Boulder, Colorado

- Office of Weights and Measures

BOLLDER LABORATORIES

F. W. Brown, Director

Cryogenic Engineering. Cryogenic Equipment. Cryogenic Processes. Properties of Materials. Gas Liquelaction.

Radio Propagation Physics. Upper Atmosphere Research. Ionospheric Research. Regular Propagation Services. Sun-Earth Relationships.

Radio Propagation Engineering. Data Reduction Instrumentation. Modulation Systems. Navigation Systems. Radio Noise. Tropospheric Measurements. Tropospheric Analysis. Radio Systems Application Engineering.

Radio Standards. High Frequency Electrical Standards. Radio Broadcast Service. High Frequency Impedance Standards. Calibration Center. Microwave Physics. Microwave Circuit Standards. 


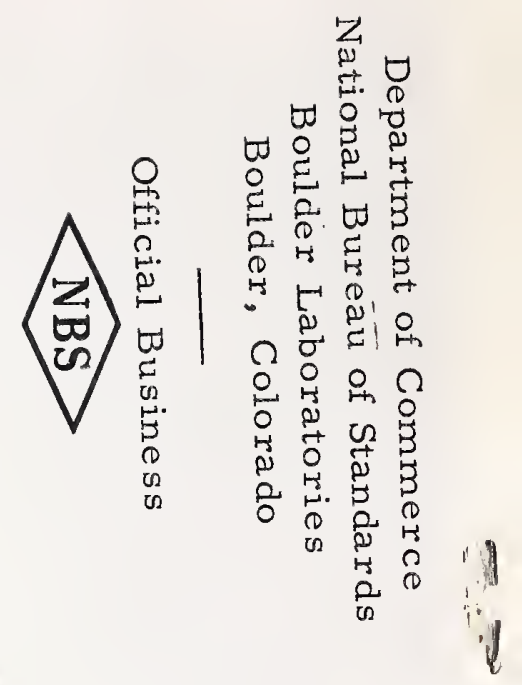

